\title{
Introduction
}

\section{Building statistical registers in countries with no administrative population registers}

\author{
Jean Michel Durr
}

Many countries are developing the use of administrative sources for their statistical production as well as to transform their population and housing census in either a fully register-based census or a census combining registers and surveys. Countries having an administrative population register, where individuals are registered at their residential address, use it as the backbone of their system, adding sources to provide information on topics not covered by the registers and to remove potential overcount. However, countries with no administrative population register tend to build statistical registers combining several administrative data sources. The issue is here not only to avoid over-count, but also undercount, and to use an appropriate methodology to determine the resident population. In addition, in countries with no population registers, the population may be very sensitive about privacy and even a statistical register may raise concern.

To take stock of the current experience of countries with no administrative population registers building statistical registers, an Invited Paper Session (IPS) was organized during the last World Statistical Congress, in July 2021 (The Haque). From this session, the following three articles present the experience of Canada, France, and New-Zealand.

\section{Canada}

Building a statistical register by linking several sources of individual data raises the issue of privacy. The paper from Canada presents how the privacy landscape in this country has evolved and shaped the statistical register infrastructure. Since 2016, Statistics Canada
(Statcan) has been exploring the possibility of adding a Statistical Population Register to its suite of statistical registers. In 2019, recognizing the importance of privacy and confidentiality and the sensitivity of Canadians to privacy issues, Statcan adopted a Necessity and Proportionality Framework and designed a privacyresponsible population linkage infrastructure rather than building a more traditional population register.

\section{France}

In 2020, the French national institute of statistics (INSEE) launched a project to create a system of interconnected registers of individuals, housing units and households to rationalize the massive use of administrative data in the production of demographic and social statistics. This project is based on the mobilization of external data, particularly administrative data, in strict compliance with the conditions for the protection of individual data. Through these registers, INSEE will have a reference universe that will allow: (i) to constitute the sampling frames as well as the calibration margins of household surveys; (ii) to measure the quality of the coverage of sources; and (iii) to match different datasets: surveys with administrative data, administrative data with administrative data to provide richer information. The paper from France presents the stakes and the context, in particular the legal context, of the implementation of these registers, and describes the main methodological principles and the proofs of concept planned for the implementation of the project.

New-Zealand

The paper from New-Zealand presents the progress 
and challenges for Stats NZ in the development of a base Statistical Person Register as part of a broader register-based statistical system in the context where there is no national unique person identifier, and no national administrative register. The paper discusses the methodology of the project, in particular probabilistic record linkage of several data sources to achieve high coverage, but also the technological challenges of combining data systems that have been built over time without an overall integrated design. In addition, it explains how Stats NZ manages to retain trust and confidence and develops connections with Māori organisations and communities while developing these new data assets, in respect of the Māori view of the world. 